\title{
Nutrients' Supplementation Impacts On Alcoholic Fermentation of Mixed Wort Containing Corn and Sugarcane
}

Nathalia Dias Silva ( $\nabla$ n95dias@usp.br)

Polytechnic School of University of São Paulo

Mariana Resende Alvim

Polytechnic School of University of São Paulo

Carlos Gonzalo Alvarez Rosario

Polytechnic School of University of São Paulo

Denise Crocce Romano Espinosa

Polytechnic School of University of São Paulo

Marcela dos Passos Galluzzi Baltazar

Polytechnic School of University of São Paulo

\section{Research Article}

Keywords: characterization, ethanol, specific growth rate, Ethanol Red

Posted Date: January 21st, 2022

DOI: https://doi.org/10.21203/rs.3.rs-1272300/v1

License: (a) (i) This work is licensed under a Creative Commons Attribution 4.0 International License. Read Full License 


\section{Abstract}

Background: Corn and sugarcane represent the world's most used feedstocks for ethanol production. Despite this, a single fermentation line integrating these both raw materials still require further investigations. Studies suggest that wort's nutrient deficiency or excess influences the yeast metabolism to convert sugar into ethanol. In that regard, this work aims to explore the nutrients' supplementation impacts on alcoholic fermentation of mixed wort containing $80 \% \mathrm{v} / \mathrm{v}$ corn hydrolyzate and $20 \% \mathrm{v} / \mathrm{v}$ sugarcane syrup.

Results: Corn hydrolyzate and sugarcane syrup presented a carbon/nitrogen ratio above the recommended levels for ethanol production, 229.2 C:N ratio and 322.7 C:N ratio, respectively. As a result, nitrogen was the nutrient with the highest positive impact on yeast specific growth rate (49\%), technological yield (35\%) and productivity (32\%). However, its stoichiometric yield was $5 \%$ lower than the wort without supplementation. Finally, organic acids ranged from 0.2-1.4 g. $\mathrm{L}^{-1}$, glycerol was between 4-8 g. $\mathrm{L}^{-1}$ and mannitol was under $0.05 \mathrm{~g} \cdot \mathrm{L}^{-1}$. All were under the estimated ranges for alcoholic fermentation.

Conclusions: All nutrients supplemented to the mixed wort increased the yeast specific growth rate, except calcium and iron. Moreover, Manganese, Cobalt and potassium impacted positively the stoichiometric yield and Nitrogen was the nutrient with highest technological yield. Finally, further studies should investigate an optimal nitrogen concentration in order to decrease the glycerol and drive the yeast metabolism, preferentially, for ethanol production rather than biomass production.

\section{Introduction}

In order to achieve the 2030 Agenda for sustainable development, the Sustainable Development Goals (SDG) were established and pledged by world leaders [1]. These goals include actions such as improving energy efficiency, promoting sustainable industrialization and efficient use of natural resources [2].

In contribution to the 2030 Agenda, the federal program RenovaBio was created in Brazil [3]. As the program aims to promote biofuel expansion in Brazil's energy matrix, a growth in corn ethanol is expected for the next few years [4].

Currently, corn represents $64 \%$ of the feedstocks used for ethanol production in the world while sugarcane is responsible for $26 \%$ [5]. Despite the widespread use of corn for ethanol production it is still considered less sustainable than ethanol production from sugarcane [4].

Therefore, sugarcane integration in corn ethanol plants can add some benefits for the corn ethanol industry. One of them is increasing the corn ethanol plant's sustainability $[6,7]$. It is possible, by shifting the burning of fossil fuel for burning of sugarcane bagasse [8]. Once the sugarcane juice is integrated in the corn fermentation process its bagasse can be reused to provide energy for corn ethanol plants [7].

Besides that, sugarcane addition in corn wort seems to increase ethanol yield by around 5\% [7]. It happens because sugarcane juice contributes with nutrients and sugars for yeast growing [9]. Nutrients like nitrogen, 
phosphorus, potassium, magnesium, calcium, zinc, manganese, cobalt, iron, copper and sodium play important roles in the yeast metabolism $[9,10]$.

The relationship between carbon and nitrogen is also investigated as a parameter for efficient alcoholic fermentation [11]. Into the cell, nitrogen is involved in the synthesis of biomolecules that allows yeast maintenance and reproduction [12]. Thus, nitrogen deficiency in the medium can result in stuck or sluggish fermentation, as a consequence, it can decrease the ethanol yield [13].

Furthermore, these nutrients required for yeast fermentation may be found in the wort under or above the required levels [14]. However, no study about the impacts of supplementing mixed wort containing corn and cane juice was found. To address this issue, the present study aims to assess the nutrients' supplementation impacts of mixed wort by monitoring parameters such as ethanol yield, residual sugars, organic acids and the yeast specific growth rate. Eventually, corn hydrolyzate and sugarcane syrup physicochemical characterization is also targeted as support analyses for the investigations in this paper.

\section{Materials And Methods}

\section{1 Feedstocks}

Corn hydrolyzate and sugarcane syrup was supplied by the Laboratory of Sucroenergetic and Bioenergy Technology (LTSBio), at the Agroindustry, Food, and Nutrition Department (LAN) of Luiz de Queiroz Agriculture College - ESALQ/USP/Brazil. Corn hydrolyzate was obtained by enzymatic hydrolysis using alpha-amylase and amyloglucosidase enzymes at the LTSbio's pilot plant. Differently, sugarcane syrup was

produced by sugarcane juice treatment in sugar and alcohol plants in Piracicaba/Brazil. Both raw materials were stored at $-4^{\circ} \mathrm{C}$ in order to avoid sugar degradation.

\section{2 Feedstock physicochemical characterization}

Corn hydrolyzate and sugarcane syrup were analyzed in regard to its carbohydrate content, $\mathrm{pH}$, density and the following nutrients: carbon, nitrogen, calcium, magnesium, manganese, sodium, potassium, phosphorus, zinc, copper, iron and cobalt.

\subsubsection{Determination of carbohydrate content}

Carbohydrate content was analyzed by ion chromatography [15] using the column metrosep carb 2 250/4.0 coupled to an amperometric detector. Before injection, ultrapure water was added to the samples in $10 \mathrm{~mL}$ volumetric flasks to achieve a 1:250 dilution. Subsequently, the samples were filtered in a filter of $0.22 \mu \mathrm{m}$ and analyzed.

The parameters used as well as their values to quantify carbohydrate content by ion chromatography is shown in Table 1. 
Table 1

Parameters to measure carbohydrates content by ion chromatography

\begin{tabular}{|ll|}
\hline Parameter & Value \\
\hline Eluent & $\begin{array}{l}200 \mathrm{mmol} / \mathrm{L} \text { of sodium hydroxide and } \\
10 \mathrm{mmol} / \mathrm{L} \text { of sodium acetate }\end{array}$ \\
\hline Flow rate & $0.7 \mathrm{~mL} / \mathrm{min}$ \\
\hline Sample volume & $10 \mathrm{~mL}$ \\
\hline Injection volume & $5 \mu \mathrm{L}$ \\
\hline Run-time for standard & $22 \mathrm{~min}$ \\
\hline Run-time for sample & $40 \mathrm{~min}$ \\
\hline Column temperature & $35^{\circ} \mathrm{C}$ \\
\hline Maximum pressure & $20 \mathrm{MPa}$ \\
\hline Calibration range & $1-800{\mathrm{mg} . \mathrm{L}^{-1}}^{-1}$ \\
\hline Standards & Carbohydrates kit (Sigma-Aldrich) \\
\hline
\end{tabular}

2.2.2 Determination of carbon and nitrogen content

Nitrogen and carbon were evaluated by TOC analyzer (TOC-L, Shimadzu). The Nitrogen Total - NT calibration range was between $0.5-1,000 \mathrm{mg} . \mathrm{L}^{-1}$. On the other hand, total organic carbon - TOC and inorganic carbon - IC were estimated in a calibration range from $10 \mathrm{mg} \cdot \mathrm{L}^{-1}$ to $1000 \mathrm{mg} \cdot \mathrm{L}^{-1}$. Potassium biphthalate was used as calibration standard for TOC measurements while the IC was evaluated using sodium bicarbonate and sodium carbonate standards. Sodium nitrate was the calibration standard for NT measurements.

The samples were diluted to 1:1000 in volumetric flasks with ultrapure water. Subsequently, they were filtered by a $0.22 \mu \mathrm{m}$ filter and their $\mathrm{pH}$ were adjusted to $2-3$ by adding a drop of sodium chloride solution $37 \% \mathrm{~m} / \mathrm{v}$.

\subsubsection{Determination of other nutrients}

The other nutrients: Calcium, Magnesium, Manganese, Sodium, Potassium, Phosphorus, Zinc, Copper, Iron and Cobalt were measured by inductively coupled plasma optical emission spectrometry - (ICP OES).

Corn hydrolyzate and sugarcane were digested by wet oxidation in order to carry out the analyses in ICPOES. The methodology applied was adapted from the method note compendium of the MARS 6 microwave (CEM) [16]. Nitric acid and hydrogen peroxide were used in the acid digestion until the samples became colorless and particle free [16]. After that, the solution acquired was completed with water up to $50 \mathrm{~mL}$. Lastly, it was filtered in a filter of $0.22 \mu \mathrm{m}$ and analyzed. 
The calibration curves ranged from 0.01 to $10 \mathrm{mg} \cdot \mathrm{L}^{-1}$ for the nutrients evaluated. Commercial standards from (Specsol) at 1,000 mg. $\mathrm{L}^{-1}$ were diluted with ultrapure water in order to prepare the calibration curves for ICP-OES analyses.

Density and $\mathrm{pH}$ were determined using a $\mathrm{pH}$-meter and a densimeter, respectively.

\subsection{Fermentation broth}

The first step to prepare the fermentation broths was to filter the corn hydrolyzate in a 0.75 micrometer sieve to avoid solids in the wort. Subsequently, the corn hydrolyzate and the sugarcane syrup were diluted to approximately $121 \mathrm{~g} . \mathrm{L}^{-1}$ of the total reducing sugar (TRS). At the end, the mixed wort was obtained blending $80 \% \mathrm{v} / \mathrm{v}$ corn hydrolyzate and $20 \% \mathrm{v} / \mathrm{v}$ sugarcane syrup.

\subsubsection{Preparation of nutrients solutions}

Twelve fermentation broths were prepared by adding nutrients solutions into the mixed wort. The nutrients concentration supplied was determined considering the values described in Table $2[17,18]$. In addition, the concentration of each nutrient supplemented into the mixed wort, as well as the chemical form supplied is shown in Table 2.

Table 2

Conditions evaluated in the mixed wort supplementation tests $[17,18]$

\begin{tabular}{|lll|}
\hline $\begin{array}{l}\text { Nutrient } \\
\text { added/condition }\end{array}$ & $\begin{array}{l}\text { Chemical form supplied in culture } \\
\text { media }\end{array}$ & $\begin{array}{l}\text { Concentration of the element supplied } \\
\left(\mathbf{m g} \cdot \mathrm{L}^{-1}\right)\end{array}$ \\
\hline Calcium & calcium Sulfate & 120 \\
\hline Magnesium & magnesium Sulfate & 135 \\
\hline Manganese & manganese (II) Sulfate & 21.50 \\
\hline Potassium & sodium Sulfate & 200 \\
\hline Phosphorus & potassium chloride & 750 \\
\hline Zinc & potassium phosphate & 311 \\
\hline Copper & zinc Sulfate heptahydrate & 5.25 \\
\hline Iron & copper Sulfate & 7 \\
\hline Cobalt & iron Sulfate & 0.20 \\
\hline Nitrogen & cobalt (II) sulfate heptahydrate & 10 \\
\hline Mixed wort & ammonium sulfate & 2,970 \\
\hline
\end{tabular}

2.4 Yeast culture (inoculum) 
The $S$. cerevisiae strain Ethanol Red ${ }^{\mathrm{TM}}$ was kindly provided by the Bioprocess Engineering Laboratory - BELa from the University of São Paulo, Brazil. Furthemore, it was stocked at $-80^{\circ} \mathrm{C}$ into $1 \mathrm{~mL}$ cryogenic tubes containing $80 \% \mathrm{v} / \mathrm{v}$ yeast cells in YPD broth and $20 \% \mathrm{v} / \mathrm{v}$ glycerol.

To prepare the fermentation pre-inoculum, $1 \mathrm{~mL}$ from the Ethanol Red kept in the cryogenic tubes was added in $100 \mathrm{~mL}$ of sterilized YPD broth $\left(20 \mathrm{~g} . \mathrm{L}^{-1}\right.$ bacteriological peptone, $20 \mathrm{~g} \cdot \mathrm{L}^{-1}$ glucose and $10 \mathrm{~g} . \mathrm{L}^{-1}$ yeast extract). The previous inoculum was kept overnight in $250 \mathrm{~mL}$ conical flasks cultivated at $30^{\circ} \mathrm{C}$ [19], shaking at $180 \mathrm{rpm}$ in rotary shaker. Thereafter, the pre-inoculum was transferred to another conical flask containing sterilized YPD broth. Finally, it was kept overnight under the same conditions above in order to obtain the inoculum [10].

\subsection{Alcoholic fermentation}

Alcoholic fermentation was conducted in microplates for ELISA to evaluate Ethanol Red's growth kinetics and in falcon tubes to assess the metabolites production. Furthermore, the fermentations were carried out with mixed wort without sterilization procedures. The influence of microbial contaminants in the fermentation was assessed by measuring the alcoholic fermentation subproducts: mannitol, succinic acid, lactic acid, acetic acid and glycerol.

\subsubsection{Fermentation in microplate for ELISA}

Fermentations in the microplate for ELISA were conducted in solid plates with 96 round bottom wells. The wells were filled with $150 \mu \mathrm{L}$ of mixed wort, $40 \mu \mathrm{L}$ of nutrient solution and $10 \mu \mathrm{L}$ of yeast inoculum (which meant a initial yeast concentration around 0.2 absorbance).

The Infinite 200 PRO was the multimode plate reader used to evaluate the Ethanol's Red growth kinetics by measuring its absorbance at $600 \mathrm{~nm}$. About the conditions setted, the growth kinetics were evaluated at $30^{\circ} \mathrm{C}$, every 20 minutes during 18.3 hours. The equipment orbital shaking amplitude and duration was defined in $1 \mathrm{~mm}$ and 27 seconds, respectively.

\subsubsection{Fermentation in falcon tubes}

During the fermentations carried out in falcon tubes, glucose, fructose, sucrose and maltose were the TRS monitored at the beginning and at the end of each fermentation. The metabolites selected to evaluate the fermentation quality were ethanol, glycerol, mannitol, acetate, lactate and succinate.

Before starting, falcon tubes were filled with $15 \mathrm{~mL}$ of mixed wort and $5 \mathrm{~mL}$ of nutrient solution. In addition, $1 \mathrm{~mL}$ of Ethanol Red inoculum was added, in order to start the fermentation with a yeast concentration of 0.2 absorbance.

Carbon dioxide loss was monitored by measuring the falcon tube's mass. Besides that, the fermentation was stopped when variations in the falcon tube's mass were less than 0.02 grams.

Finally, the falcon tubes were kept at $30^{\circ} \mathrm{C}$ [14], shaking at $180 \mathrm{rpm}$ in a rotary shaker. Aliquots of $3 \mathrm{~mL}$ were taken from each falcon tube to evaluate the TRS and metabolites. The aliquots were taken at the 
beginning and at the end of the alcoholic fermentations.

2.6 Determination of ethanol, glycerol, organic acids and mannitol

The Glycerol and mannitol produced in each fermentation was measured by ion chromatography according to the method developed to evaluate carbohydrates content (Table 1).

The ethanol and organic acids (lactic, acetic and succinic) were assessed by high-performance liquid chromatography (HPLC) using the column Bio-rad Aminex HPX-87H coupled to a refractive index (RI) detector.

Before injection, ultrapure water was added to the samples in $10 \mathrm{~mL}$ volumetric flasks to achieve a 1:10 dilution. Subsequently, the samples were filtered in a filter of $0.22 \mu \mathrm{m}$ and analyzed. The parameters setted up to conduct the analyses by HPLC can be seen in Table 3 .

Table 3

Parameters to measure organic acids by HPLC

\begin{tabular}{|ll|}
\hline Parameter & Value \\
\hline Eluent & $5 \mathrm{mmol} / \mathrm{L}$ of sulfuric acid $\left(\mathrm{H}_{2} \mathrm{SO}_{4}\right)$ \\
\hline Flow rate & $0.6 \mathrm{~mL} / \mathrm{min}$ \\
\hline Sample volume & $1 \mathrm{~mL}$ \\
\hline Injection volume & $10 \mu \mathrm{L}$ \\
\hline Run-time for sample and standard & $30 \mathrm{~min}$ \\
\hline Column temperature & $60^{\circ} \mathrm{C}$ \\
\hline Calibration range & $1-20$ g.L-1 \\
\hline Standards & commercially standards (Sigma-Aldrich) \\
\hline
\end{tabular}

Calculations related to the alcoholic fermentations are described in Table $4[20,21]$. 
Table 4

Parameters to evaluate fermentation

\begin{tabular}{|c|c|}
\hline Variable & Method \\
\hline Alcohol content\% (v/ v) & $C\left[\frac{\text { etanol }, f]}{789} \times 100\right.$ \\
\hline Technological yield & $\frac{C[\text { etanol, } f]}{0,511 \times C[T R S, i]} \times 100$ \\
\hline Stoichiometric yield & $\frac{C[\text { etanol }, f-\text { etanol }, i]}{0,511 \times C[T R S, i-T R S, f]} \times 100$ \\
\hline Ethanol productivity & $C[\underset{\bar{t}}{\operatorname{etanol}, f]}$ \\
\hline \multicolumn{2}{|l|}{ Wherein: } \\
\hline \multicolumn{2}{|c|}{$C[$ ethanol, $f]=$ net concentration of ethanol in the fermented wort } \\
\hline \multicolumn{2}{|c|}{$\mathrm{C}[T R S, \bar{\lambda}]=$ concentration of TRS in the wort } \\
\hline$t=$ fermentation time & \\
\hline
\end{tabular}

\subsection{Statistical analyses}

The statistical analyses and graphs were accomplished using the software excel. It is noteworthy that the experiments were performed in triplicate and the results were expressed as means followed by its standard deviation.

\section{Results And Discussions}

\subsection{Feedstock physicochemical characterization}

Before starting alcoholic fermentation tests, this study carried out a physicochemical characterization of both feedstocks employed. The first analysis conducted was the carbohydrate content determination by ion chromatography.

The main fermentable sugar concentrations found in corn hydrolyzate and sugarcane syrup is shown in Table 5. Values for TRS were calculated including the glucose, fructose, sucrose and maltose amounts. Once sucrose is not defined as a reducing sugar, its contribution for the TRS value was added as the sucrose amount divided per 0.95 [22]. 
Table 5

Feedstock carbohydrate content determined by ion chromatography

\begin{tabular}{|lll|}
\hline Analyses & Corn hydrolyzate $\left(\mathbf{g} . \mathrm{L}^{-1}\right)$ & Sugarcane Syrup $\left(\mathbf{g} \cdot \mathbf{L}^{-1}\right)$ \\
\hline Glucose & $369.1 \pm 10.0$ & $34.1 \pm 1.8$ \\
\hline Fructose & $5.2 \pm 0.6$ & $46.2 \pm 0.4$ \\
\hline Sucrose & - & $1,317 \pm 8.5$ \\
\hline Maltose & $18.0 \pm 0.7$ & - \\
\hline TRS & $392.2 \pm 10.9$ & $1,466.6 \pm 10.3$ \\
\hline
\end{tabular}

During corn enzymatic hydrolysis, the starch present into endosperm is mostly converted to glucose by enzymes like alpha-amylase and amyloglucosidase. Consequently, glucose was the sugar from corn hydrolyzate that presented the largest proportion of TRS composition, $94.1 \%$. Maltose and fructose were quantified in minor proportions, $4.6 \%$ and $1.3 \%$, respectively.

Looking at the sugarcane carbohydrate content, it was noted that sucrose was the sugar with the higher contribution to TRS composition, $94.5 \%$. As expected, no maltose was found in sugarcane syrup [23,24]. Lastly, fructose represented $3.2 \%$ and glucose $2.3 \%$ of TRS composition.

Sugarcane syrup exhibited $73.3 \%$ higher TRS concentration than corn hydrolyzate. It happened because the sugarcane juice used to make the syrup was previously treated by heating and it concentrated the juice.

Other implications from this previous treatment were also observed in the results from the total organic carbon analyzer. Since sugarcane syrup was concentrated before, its parameters evaluated in Table 6 returned higher values than the parameters evaluated for corn hydrolyzate.

As sugars are included in the organic carbon composts and the feedstocks were rich in sugars (Table 6), the total organic carbon - TOC in the samples were thousand times higher than the inorganic carbon - IC.

The optimum C:N ratio for ethanol production by $\mathrm{S}$. cerevisiae in tapioca starch is described as $35.2 \mathrm{C}: \mathrm{N}$ ratio [11]. Taking this to account, C:N ratio analyses indicates that corn hydrolyzate and sugarcane syrup are rich in carbon, nevertheless, they are poor in nitrogen for ethanol production. 
Table 6

Feedstock carbon and nitrogen characterization by total organic carbon analyzer

\begin{tabular}{|lll|}
\hline Analyses & Corn hydrolyzate & Sugarcane Syrup \\
\hline Total organic carbon -TOC $\left(\mathrm{g} . \mathrm{L}^{-1}\right)$ & $151.9 \pm 0.2$ & $450.2 \pm 12.3$ \\
\hline Inorganic carbon - IC $\left(\mathrm{g} . \mathrm{L}^{-1}\right)$ & $0.2 \pm 0.0$ & $0.2 \pm 0.0$ \\
\hline Total carbon - TC (g. L $\left.{ }^{-1}\right)$ & $152.1 \pm 45.7$ & $450.4 \pm 12.4$ \\
\hline Total nitrogen - TN (g. L $\left.{ }^{-1}\right)$ & $0.7 \pm 0.1$ & $1.4 \pm 0.2$ \\
\hline Carbon/Nitrogen - (C/N ratio) & $229.2 \pm 25.2$ & $322.7 \pm 25.7$ \\
\hline Total reducing sugar/Nitrogen - (TRS/Nitrogen) & $592.9 \pm 45.7$ & $1,051.5 \pm 102.8$ \\
\hline
\end{tabular}

In addition to carbon and nitrogen, other nutrients can improve yeast growth and fermentation. However, when the parameters exceed yeast requirements, they can play a role in inhibiting yeast growth or ethanol production [25].

Comparing the results acquired in Table 7 with the recommended levels for yeast fermentation proposed in the literature, it was noted that some nutrients were out of recommendation range. Regarding both feedstocks, Phosphorus, Magnesium and iron exceeded the recommended range $[17,18]$ while Manganese and Cobalt were under the recommended levels.

The nutrient content described in Table 7 refers to the total concentration of each element analyzed. In addition, a TRS/Nutrient ratio calculated for both feedstocks are shown in Table 7. Based on the TRS/Nutrient ratio, it is possible to estimate the concentration of nutrients present in wort composed of corn and sugarcane. Besides that, some nutrients may be present in the feedstocks in not assimilable forms for the yeast metabolism [26]. Finally, due to aspects such as variety of soil, seed and climate, the composition of corn hydrolyzate and sugarcane syrup can vary when compared to other references [26]. 
Table 7

Feedstock physicochemical characterization by inductively coupled plasma optical emission spectrometry - (ICP OES)

\begin{tabular}{|lllll|}
\hline $\begin{array}{l}\text { Nutrient } \\
\text { analyzed }\end{array}$ & $\begin{array}{l}\text { Sugarcane } \\
\text { Syrup } \\
\left(\mathbf{m g} . \mathrm{L}^{-1}\right)\end{array}$ & $\begin{array}{l}\text { Sugarcane Syrup } \\
\text { TRS/Nutrient }\end{array}$ & $\begin{array}{l}\text { Corn hydrolyzate } \\
\left(\mathrm{mg} . \mathrm{L}^{-1}\right)\end{array}$ & $\begin{array}{l}\text { Corn hydrolyzate } \\
\text { TRS/Nutrient }\end{array}$ \\
\hline Potassium & $\begin{array}{l}1,633.9 \pm \\
65.1\end{array}$ & $0.9 \pm 0.0$ & $702.5 \pm 22.6$ & $0.6 \pm 0.0$ \\
\hline Phosphorus & $\begin{array}{l}485.7 \pm \\
18.2\end{array}$ & $3.0 \pm 0.1$ & $564.3 \pm 11.7$ & $0.7 \pm 0.0$ \\
\hline Magnesium & $\begin{array}{l}316.8 \pm \\
31.6\end{array}$ & $4.6 \pm 0.5$ & $144.3 \pm 7.1$ & $2.7 \pm 0.1$ \\
\hline Sodium & $277.4 \pm$ & $5.3 \pm 0.6$ & $67.8 \pm 7.9$ & $5.8 \pm 0.7$ \\
\hline Calcium & $146.9 \pm 5.5$ & $10 \pm 0.4$ & $30.5 \pm 3.0$ & $12.9 \pm 1.2$ \\
\hline Zinc & $11.4 \pm 1.5$ & $128.9 \pm 16.1$ & $1.5 \pm 0.0$ & $261.5 \pm 0.0$ \\
\hline Iron & $11.4 \pm 1.5$ & $128.9 \pm 16.1$ & $2.2 \pm 0.8$ & $181.0 \pm 65.4$ \\
\hline Copper & $12.3 \pm 1.5$ & $119.7 \pm 16.1$ & $2.7 \pm 0.8$ & $147.1 \pm 42.1$ \\
\hline Cobalt & $9.6 \pm 1.5$ & $152.4 \pm 26.9$ & $2.3 \pm 0.3$ & $168.1 \pm 22.6$ \\
\hline Manganese & $5.3 \pm 0.0$ & $279.3 \pm 0.0$ & $2.3 \pm 0.6$ & $168.1 \pm 37.7$ \\
\hline
\end{tabular}

The $\mathrm{pH}$ value and density measured for corn hydrolyzate and sugarcane syrup is illustrated in Table 8 . The $\mathrm{pH}$ feedstocks were similar and they were slightly above the optimal $\mathrm{pH}$ for $\mathrm{S}$. cerevisiae fermentation, which is setted between $4.0-5.0$ [12].

Table 8

Others feedstock physicochemical analysis

\begin{tabular}{|lll|}
\hline Analyses & Corn hydrolyzate & Sugarcane Syrup \\
\hline $\mathrm{pH}$ & $5.80 \pm 0.04$ & $5,70 \pm 0.02$ \\
\hline Density $\left(\mathrm{kg} / \mathrm{m}^{3}\right)$ & $1.10 \pm 0.01$ & $1,380 \pm 0.02$ \\
\hline
\end{tabular}

\subsection{Fermentation in microplate for ELISA}

The alcoholic fermentations in microplates for ELISA were monitored for 18.3 hours. After this time, the yeast reached the stationary phase for all conditions evaluated. Despite the variation observed in the initial absorbance, Ethanol Red presented a final absorbance up to 0.43 for all conditions. Thus, by making a correlation between dry mass and absorbance, it was possible to find about $15 \mathrm{mg}$ of Ethanol Red biomass production based on dry mass. 
In Figure 1, a comparison is shown between the growth profile of Ethanol Red in mixed wort supplemented with eleven different conditions and without supplementation. It was noticed that Ethanol Red was able to grow in all conditions. As both feedstocks were diluted to achieve approximately $121 \mathrm{~g} \cdot \mathrm{L}^{-1} \mathrm{TRS}$, the nutrients presented in the mixed wort were in lower concentrations than those found in the feedstocks (Table 7).

Bioethanol is a primary metabolite, in this sense, its production is associated with yeast growth [36]. It means that ethanol production profile tends to be similar to Ethanol Red growth kinetics presented in Figure 1.

The specific growth rates obtained for Ethanol Red in mixed wort supplemented with eleven nutrients and with no supplementation is illustrated in Figure 2. Nitrogen, cobalt, sodium, phosphorus, magnesium, potassium, zinc, copper and manganese expressed an increase in the yeast specific growth rate. Between them, nitrogen was the nutrient with the highest positive impact in the yeast growth rate, up to $49 \%$. This result suggests that the nutrients mentioned above, mainly nitrogen, might contribute to increasing the alcoholic fermentations' yield.

When yeast reaches higher specific growth rates, the fermentation time is reduced and the ethanol productivity is increased [25]. Furthermore, it allows the yeast to dominate the process and inhibit the activity from microbial contaminants $[27,28]$. Consequently, parallel reactions carried out by microbial contaminants are performed at lower rates and more sugar is converted to ethanol $[27,28]$. All these points mentioned above represent advancements for the ethanol industrial process.

Unlike nitrogen, iron and calcium decreased the yeast growth rate more than $22 \%$. Iron is an enzyme catalytic center and it acts as a cofactor in the yeast respiratory activity and growth [18]. However, excess iron induces cell death, and it can reduce enzymatic activities from enzymes such as pyruvate and succinate dehydrogenases [25].

Despite calcium improving yeast tolerance to ethanol stress, there are discussions about its required levels for yeast growth $[25,9,18]$. Calcium roles in the cell are related to acts on membrane function and structure. Thus, when it exceeds the yeast necessity, calcium can interfere in amino acid and magnesium uptake and it blocks cell processes involving $\mathrm{Mg}^{2+}$ [25].

For yeast growth, calcium and iron recommended levels are around $180 \mathrm{mg} . \mathrm{L}^{-1}$ and $0.17 \mathrm{mg} \cdot \mathrm{L}^{-1}[25]$. Taking into account the amount of the nutrients found in the feedstocks characterization (Table 7), it is noticed that calcium and iron were present in the sugarcane syrup in higher amounts than the recommended levels. In regard to corn hydrolyzate only iron exceeds the recommended level.

\subsection{Fermentation in falcon tubes}

The fermentation was stopped when the variations in falcon tubes' mass were less than 0.02 grams. In that order, the alcoholic fermentations in falcon tubes lasted for 52 hours. 
As the yeast was supplied with approximately $121 \mathrm{~g} . \mathrm{L}^{-1}$ of TRS, it was expected to find a theoretical ethanol concentration up to $61.8 \mathrm{~g} \cdot \mathrm{L}^{-1}$. However, during alcoholic fermentation, sugar can be deviated to produce other subproducts as glycerol, organic acids or biomass rather than ethanol. The theoretical equation proposed by Gay-Lussac to describe sugar conversion from corn and sugarcane in ethanol and carbon dioxide is shown in Figure 3 [29]. In addition, it also summarizes cell metabolism during alcoholic fermentation $[20,21,30]$.

The condition that came closest to the theoretical concentration of ethanol was mixed wort supplemented with nitrogen. In this condition, the fermentation started with $123 \mathrm{~g} \cdot \mathrm{L}^{-1} \pm 2$ of TRS. At the end, $53 \mathrm{~g} \cdot \mathrm{L}^{-1} \pm 1$ of ethanol were produced and not all sugar consumed was converted to ethanol. As expected, part of the 99\% TRS consumed were probably transformed into biomass, glycerol, storage carbohydrates and fermentation byproducts as succinic acid [9]. Parallel reactions such as Maillard reactions and those carried out by microbial contaminants may also have been responsible for sugar consumption [9].

When nitrogen is available in the medium in assimilable forms, it allows the biosynthesis of new molecules for yeast multiplication [31,32]. Therefore, the yeast catabolism is accelerated in order to produce more ATP for cell maintenance and growing. As a consequence, more hexoses are converted and more ethanol and carbon dioxide are excreted in the medium. Peptides, proteins, polyamides, nucleic acids and vitamins are some of the biomolecules produced with the nitrogen uptake by the yeast [32].

Nitrogen, magnesium and zinc deficiencies or calcium excess are reported as the main factors to stuck or sluggish fermentations [9]. Nevertheless, the results indicate that only nitrogen was necessary to avoid stuck or sluggish fermentations, once it was the only condition in which residual TRS was almost zero (1 $\left.\mathrm{g} . \mathrm{L}^{-1}\right)$. All other conditions remained with more than $32 \mathrm{~g} \cdot \mathrm{L}^{-1}$ of residual TRS. The ethanol and glycerol production as well as the initial and residual TRS in the twelve conditions evaluated is described in Figure 4.

In regard to the other metabolites measured in this study, it was noticed that glycerol reached the average value of $4 \mathrm{~g} \cdot \mathrm{L}^{-1} \pm 1.2$ for all conditions, except for the mixed wort supplemented with nitrogen, which was 8 g. $\mathrm{L}^{-1} \pm 0.4$. In alcoholic fermentation, approximately $10 \%$ of TRS provided is converted to glycerol $[9,33]$. Since the fermentation in falcon tubes started with an average of $121 \mathrm{~g} \cdot \mathrm{L}^{-1}$ of TRS, the values found are under the expected range $\left(12 \mathrm{~g} \cdot \mathrm{L}^{-1}\right)$. Glycerol is an indicator of the osmotic stress upon the yeast [26]. Furthermore, glycerol is associated with cell growth, once it works as an electron acceptor to maintain the $\mathrm{NADH}$ redox balance in anaerobiosis [10,34]. In that order, these were the main reasons why glycerol content in the mixed wort containing nitrogen was higher than the values found in the other conditions.

As described in Table 4, the ethanol yield was calculated in two different ways. Looking at the technological yield's results, it demonstrated that iron, copper and calcium had a negative impact on this parameter. Besides the negative effects of iron and calcium upon the yeast metabolism, already discussed previously, excess copper can promote cell death $[9,25]$. Lastly, its impact on the yeast can vary according to the strains [25]. 
Nitrogen, manganese, magnesium and potassium increase the ethanol technological yield. This result reinforces the evidence that both feedstocks were with their carbon/nitrogen ratio (Table 6) above the recommended levels for ethanol production, $35.2 \mathrm{C} / \mathrm{N}$ ratio [11].

About the stoichiometric yield, it was observed that its values ranged from $74-92 \%$. Notwithstanding the fact that nitrogen supplementation promoted the highest ethanol productivity, only manganese, cobalt and potassium reached stoichiometric yields higher than the condition with no supplementation. Furthermore, it is noteworthy that these three conditions presented a stoichiometric yield between the current declared in the ethanol industry (90-92\%) [35].

Manganese is reported as a cofactor to enzymatic activities and may stimulate yeast growth and fermentation [25]. About potassium, it is involved in many activities of yeast's anabolism and catabolism [37]. It helps the cell to cope with osmotic stress and improves its tolerance to ethanol. In addition, potassium acts as a cofactor, and it is associated with the uptake of nutrients as phosphate [25, 37]. Finally, cobalt is also an element required as a structural stabilizer and for the synthesis of coenzymes and vitamins as cobalamin [37]. The stoichiometric yield, the technological yield and the productivity are shown in Figure 5 for all conditions evaluated.

Although ethanol is the product of interest, its presence in concentrations higher than $10 \% \mathrm{w} / \mathrm{v}$ can provoke a reduction in the yeast metabolic activity [38]. In addition, it induces toxic effects against the structure of the cell membrane [26]. As a result, it can inhibit the yeast growth and glucose conversion to ethanol.

Despite wort supplementation with nitrogen having reached the highest ethanol content $(7 \% \pm 0.1)$, it was under the described levels to avoid ethanol stress on the yeast.

The alcohol content in volume/volume basis for all conditions evaluated can be seen in Figure 6.

The mixed wort supplementation with nitrogen was the condition with the highest increases in the yeast specific growth rate (49\%), productivity (32\%) and the technological yield (35\%). However, its stoichiometric yield was $5 \%$ lower than the wort with no supplementation. It occurred because nitrogen supplementation was the only condition which promoted the consumption of more than $99 \%$ of TRS.

Taking into account the fact that the nitrogen concentration added $\left(2.97 \mathrm{~g} \cdot \mathrm{L}^{-1}\right)$ was enough to consume almost all TRS supplied, further research with less nitrogen concentrations should be carried out. In that order, a nitrogen concentration to decrease the glycerol produced and drive the yeast metabolism preferentially for ethanol production rather than biomass production could be established.

In alcoholic fermentation, the yeast can produce lactic acid [33]. However, most of the lactic acid produced comes from the microbial contaminants' metabolism, mainly Lactobacillus [29,32]. The concentrations of lactic acid measured during the fermentations were about $0.3 \mathrm{~g} . \mathrm{L}^{-1} \pm 0.1$, except for phosphorus $\left(0.6 \mathrm{~g} . \mathrm{L}^{-1}\right.$ \pm 0.1 ). This indicates that microbial contaminants or yeast metabolism did not deviate large amounts of sugar from producing ethanol to producing lactic acid. Another hypothesis is that during the sugarcane juice treatment to obtain syrup, the microbial load may have been reduced by the heating. 
Acetic acid is produced by ethanol oxidation and it causes toxic effects to yeast [33,32]. However, this organic acid can be produced by the own $S$. cerevisiae metabolism or by microbial contamination. The acetic acid measured was under the levels to avoid toxic effects to yeast [9]. Mixed wort supplemented with nitrogen was the condition which presented the highest acetic acid concentration, $0.8 \mathrm{~g} \cdot \mathrm{L}^{-1} \pm 0.1$ while all the others returned values equal or less than $0.2 \mathrm{~g} . \mathrm{L}^{-1} \pm 0.2$ of acetic acid.

Succinic acid is usually excreted in the medium by the yeast to inhibit bacterial growth [33]. The succinic acid concentrations evaluated in the fermentations were up to $1.4 \mathrm{~g} \cdot \mathrm{L}^{-1} \pm 0.2$ which were under the estimated ranges for alcoholic fermentation [32]. The organic acids measured in the fermented mixed wort is shown in Figure 7.

Accordingly, mannitol is used as an indicator of microbial contaminants in fermented wort [29]. As the mannitol concentration in the fermented wort was less than $0.05 \mathrm{g.L} \mathrm{L}^{-1}$, it suggests that Ethanol Red was the dominant microorganism acting in the fermentation.

\section{Conclusions}

The feedstock physicochemical characterization showed that corn hydrolyzate and sugarcane syrup presented a carbon/nitrogen ratio above the recommended levels for ethanol production (35.2 C:N ratio). As a consequence, the nitrogen was the nutrient with the higher impact on the alcoholic fermentation. The mixed wort supplemented with nitrogen increased the yeast specific growth rate $(49 \%)$, the technological yield (35\%) and productivity (32\%).

The stoichiometric yield was $5 \%$ lower than the wort without supplementation for the nitrogen condition. Mainly, because nitrogen was the only supplement which promoted the consumption of more than $99 \%$ of TRS (1 g. $\left.\mathrm{L}^{-1}\right)$, while the others remained with more than $32 \mathrm{~g} . \mathrm{L}^{-1}$. Thus, further research should be carried out in order to find out a nitrogen concentration which could decrease the glycerol produced and drive the yeast metabolism preferentially for ethanol production rather than biomass production.

Iron and calcium were the nutrients which decreased both the yeast specific growth rate and the fermentative parameters. Finally, Manganese, Cobalt and potassium impacted positively the ethanol yield.

In regard to the other metabolites measured, it was noticed that nitrogen supplementation returned the higher glycerol content due to the higher levels of ethanol produced and cell growth. At the end, mannitol and all byproducts measured: glycerol and the organic acids (acetic, lactate and succinic acid) were under the estimated ranges for alcoholic fermentation. As a result, we conclude that most of the TRS provided was driven by Ethanol Red for its growing and ethanol production rather than by microbial contaminants in parallel reactions.

\section{Abbreviations}


YPD: yeast extract peptone dextrose; TRS: total reducing sugar; ATP: Adenosine triphosphate; C: carbon; $\mathrm{C} / \mathrm{N}$ : Carbon/Nitrogen ratio; ICP OES: inductively coupled plasma optical emission spectrometry; ELISA: Enzyme-Linked Immunosorbent Assay; SDG: Sustainable Development Goals; TOC: Total organic carbon; IC: Inorganic carbon; TC: Total carbon; TN: Total nitrogen; LTSBio: Laboratory of Sucroenergetic and Bioenergy Technology; LAN: Agroindustry, Food, and Nutrition Department; HPLC: high-performance liquid chromatography; Rl: refractive index.

\section{Declarations}

\section{Authors' contributions}

NDS, MRA, CGA and MPGB designed the study. DCRE supervised the study carried out. NDS performed the experiments, analyzed the data and wrote the manuscript. All authors read and approved the final manuscript.

\section{Authors' information}

Affiliation: Department of Chemical Engineering, Polytechnic School of University of São Paulo, São Paulo, Brazil.

Corresponding author: n95dias@usp.br

\section{Acknowledgements}

The authors would like to thank Dr. Prof. Antônio Sampaio from the Luiz de Queiroz Agriculture College ESALQ/USP for kindly providing the corn hydrolyzate and sugarcane syrup samples. We also thank Prof. Dr. Thiago Olitta Basso from University of São Paulo for providing the S. cerevisiae Ethanol Red ${ }^{\text {TM }}$ strain. Instrumental support provided by the Laboratory of Recycling, Waste Treatment and Extraction - LAREX and the Bioprocess Engineering Laboratory - BELa from the department of Chemical Engineering of University of São Paulo is gratefully acknowledged. Finally, we acknowledge and thank the professionals involved in the Sinochem's project for their valuable insights.

\section{Competing interests}

The authors declare that they have no competing interests.

\section{Availability of data and materials}

The datasets used and analyzed in the current study are available from the corresponding author upon reasonable request.

\section{Consent for publication}

This article is published under license to Brazilian Company of Research and Industrial Innovation EMBRAPII and Sinochem Brazil. 


\section{Ethics approval and consent to participate}

Not applicable.

\section{Funding}

The authors would like to acknowledge funding from EMBRAPII and Sinochem Brazil.

\section{References}

1. United Nations: Transforming our world: the 2030 Agenda for Sustainable Development. https://www.refworld.org/docid/57b6e3e44.html (2015). Accessed 18 Jul 2021.

2. United Nations: The 17 goals. https://sdgs.un.org/goals (2020). Accessed 18 Jul 2021.

3. National Agency for Petroleum, Natural Gas and Biofuels: RenovaBio. https://www.gov.br/anp/ptbr/assuntos/renovabio (2020). Accessed 18 Jul 2021.

4. Grassi MCB, Pereira GAG. Energy-cane and RenovaBio: Brazilian vectors to boost the development of Biofuels. Ind. Crop Prod. 2019. https://doi.org/10.1016/j.indcrop.2018.12.006

5. FAO/OECD - Food and Agriculture Organization of the United Nations. "Biofuels" OECD-FAO Agricultural Outlook 2020-2029. http://www.fao.org/publications/oecd-fao-agricultural-outlook/20202029/en. (2020). Accessed 18 Jul 2021.

6. Zahoor A, Messerschmidt K, Boecker S, Klamt S. ATPase-based implementation of enforced ATP wasting in Saccharomyces cerevisiae for improved ethanol production. Biotechnol Biofuels. 2020. https://doi.org/10.1186/s13068-020-01822-9

7. Sica P, Prado LMLM, Granja P, Carvalho EMd, Mattos EdC, Calegari RP, Silverio M, Martins BC, Baptista AS. Effects of Energy Cane (Saccharum spp.) Juice on Corn Ethanol (Zea mays) Fermentation Efficiency: Integration towards a More Sustainable Production. Fermentation. 2021. https://doi.org/10.3390/ fermentation7010030

8. Ceccato-Antonini SR, Bassi, APG, Paraluppi AL, dos Santos EGD, Matsuoka S. Deterioration and fermentability of energy cane juice. Cienc. Rural. 2017. https://doi.org/10.1590/0103-8478cr20160860

9. Walker GM, Walker RSK. Enhancing Yeast Alcoholic Fermentations. Advances in Applied Microbiology. 2018. doi:10.1016/bs.aambs.2018.05.003

10. Lino FSdO, Basso TO, Sommer MOA. A synthetic medium to simulate sugarcane molasses. Biotechnol Biofuels. 2018. doi: https://doi.org/10.1186/s13068-018-1221-x

11. Manikandan $\mathrm{K}$, Viruthagirl, $\mathrm{T}$. Optimization of $\mathrm{C} / \mathrm{N}$ ratio of the medium and fermentation conditions of ethanol production from starch using co-culture of Aspergillus niger and Saccharomyces cerevisiae. International Journal of ChemTech Research. 2010; 947:955.

12. Ünal MÜ, Chowdhury G, Şene A. Effect of temperature and nitrogen supplementation on bioethanol production from waste bread, watermelon and muskmelon by Saccharomyces cerevisiae. Biofuels. 2020. doi:10.1080/17597269.2020.1724440 
13. Labuschagne, P., Divol, B. Thiamine: a key nutrient for yeasts during wine alcoholic fermentation. Appl Microbiol Biotechnol 105, 953-973 (2021). https://doi.org/10.1007/s00253-020-11080-2

14. Fish WW, Bruton BD, Russo VM. Watermelon juice: a promising feedstock supplement, diluent, and nitrogen supplement for ethanol biofuel production. Biotechnol Biofuels 2009. https://doi.org/10.1186/1754-6834-2-18

15. Metrom: Mono-, di-, and oligosaccharides in wort. (2020). https://www.metrohm.com/engb/applications/AN-P-084?fromProductFinder=true. Accessed 15 Jul 2021.

16. CEM: MARS 6 Microwave Acid Digestion: Method Note Compendium. (2018).http://cem.com/media/contenttype/media/literature/MetNote_MARS6_Compendium.pdf. Accessed 15 Jul 2021.

17. Amorim HV, Leão RM. Alcoholic Fermentation - Science and Technology. 1rd ed. Piracicaba: Fermentec; 2005.

18. dos Santos, AM. Study of the influence of supplementation in must on the alcoholic fermentation process in batch. (2008) http://bdtd.ibict.br/vufind/Record/UFAL_b060d839fb2e0223612eb088820294af. Accessed 15 Jul 2021.

19. Tesfaw A, Assefa F. Current Trends in Bioethanol Production by Saccharomyces cerevisiae: Substrate, Inhibitor Reduction, Growth Variables, Coculture, and Immobilization. International Scholarly Research Notices. 2014. http://dx.doi.org/10.1155/2014/532852

20. Alba-Lois L, Segal-Kischinevzky C. Beer \& Wine Makers. Nature Education. 2010;3:9-17.

21. Cruz, M.L. Evaluation of operational conditions in VHG alcoholic fermentation using different strains of Saccharomyces cerevisiae. (2019). https://repositorio.ufu.br/handle/123456789/24567. Accessed 15 Jul 2021.

22. Syngenta: Sugarcane in Brazil and in the world. (2013) https://petfaem.files.wordpress.com/2013/10/cana-de-acucar4.pdf. Accessed 15 Jul 2021.

23. Vohra M, Manwar J, Manmode R, Padgilwar S, Patil S. Bioethanol production: Feedstock and current technologies. Journal of Environmental Chemical Engineering. 2014. doi:10.1016/j.jece.2013.10.013

24. Ellilä S, Fonseca L, Uchima C, Cota J, Goldman G, Saloheimo M, Sacon V, Siika-aho M. Development of a low-cost cellulase production process using Trichoderma reesei for Brazilian biorefineries. Biotechnol Biofuels. 2017. https://doi.org/10.1186/s13068-017-0717-0

25. Novozymes Bioenergy: Yeast Micronutrient and Growth Factor Requirements.https://www.novozymes.com/-/media/Project/Novozymes/Website/website/documentlibrary/Advance-your-business/Bioenergy/Yeast-Micronutrient-Requirements-2017.pdf. (2017). Accessed 15 Jul 2021.

26. Basso LC, Basso TO, Rocha SN. Ethanol production in Brazil: the industrial process and its impact on yeast fermentation. In: dos Santos Bernardes MA, editor. Recent developments and prospects. New York: INTECH Open; 2011. p. 85-100. 
27. Lopes LM, Paulillo SCL, Cherubin AR, Godoy A, Amorim HBN, Amorim HV. Tailored yeast strains for ethanol production: process-driven selection. 1rd ed. Piracicaba: Fermentec; 2015.

28. Skinner K.A., Leathers T.D. Bacterial Contaminants of fuel ethanol production. J Ind Microbiol Biotechnol. 2004; doi: 10.1007/s10295-004-0159-0

29. Lopes ML, De Lima Paulillo C, Godoy A, Cherubin A, Lorenzi MS, Henrique F, Domingos GC, de Amorim $\mathrm{BH}$ B, de Amorim HV. Ethanol production in Brazil: a bridge between science and industry. Braz J Microbiol. 2016. https://doi.org/10.1016/j.bjm.2016.10.003

30. Eder M, Sanchez I, Brice, C, Camarasa C, Legras JL, Dequin S. QTL mapping of volatile compound production in Saccharomyces cerevisiae during alcoholic fermentation. BMC Genomics 19, 166 (2018). https://doi.org/10.1186/s12864-018-4562-8

31. Monteiro B, Ferraz P, Barroca M, Cruz SHd, Collins T, Lucas C. Conditions promoting effective very high gravity sugarcane juice fermentation. Biotechnol Biofuels. 2018. https://doi.org/10.1186/s13068-0181239-0

32. Zamora F. Biochemistry of Alcoholic Fermentation. Wine Chemistry and Biochemistry, 2009. 3-26. doi:10.1007/978-0-387-74118-5_1

33. Albers E, Johansson E, Franzén CJ, Larsson C. Selective suppression of bacterial contaminants by process conditions during lignocellulose based yeast fermentations. Biotechnol Biofuels 4, 59 (2011). https://doi.org/10.1186/1754-6834-4-59

34. Modig T, Granath K, Adler L, Lidén G. Anaerobic glycerol production by Saccharomyces cerevisiae strains under hyperosmotic stress. Applied Microbiology and Biotechnology, 2, 75 (2007). 10.1007/s00253-006-0821-8

35. Basso LC, de Amorim, H., de Oliveira AJ, Lopes ML. Yeast selection for fuel ethanol production in Brazil. FEMS Yeast Research. 2008 doi:10.1111/j.1567-1364.2008.00428.x

36. Sanchez S, Demain AL. Metabolic regulation and overproduction of primary metabolites. Microbial biotechnology. 2008. doi:10.1111/j.1751-7915.2007.00015.x

37. Walker G. Metals in Yeast Fermentation Processes. Advances in Applied Microbiology, 54 (2004). https://doi.org/10.1016/S0065-2164(04)54008-X

38. Dorta C, Oliva PN, de Abreu MSN, Nicolau N, Nagashima Al. Synergism among lactic acid, sulfite, pH and ethanol in alcoholic fermentation of Saccharomyces cerevisiae (PE-2 and M-26). 2006. doi: $10.1007 /$ s11274-005-9016-1

\section{Figures}


a)

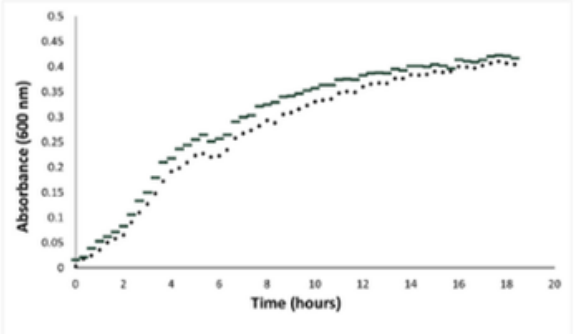

- Mixed wort - Phosphor 311 ppm

d)

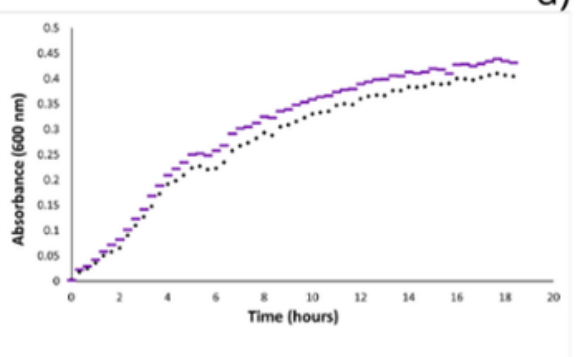

- Mixed wort

- Manganese 21.5 ppm

g)

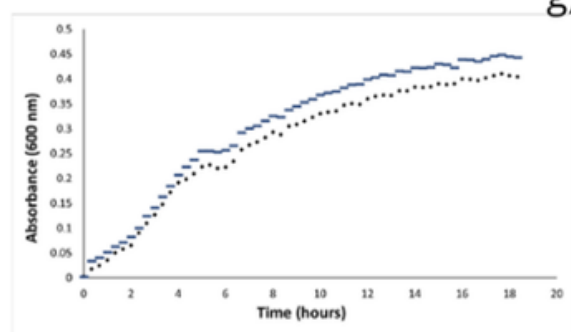

- Mixed wort

- Copper 7 ppm

j)

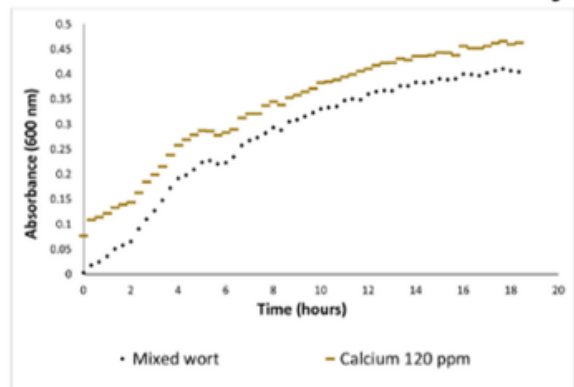

b)

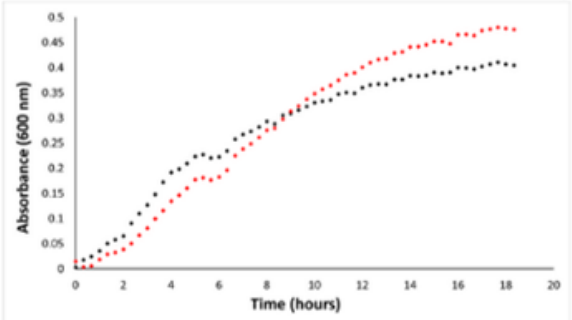

- Mixed wort - Nitrogen 2970 ppm

e)

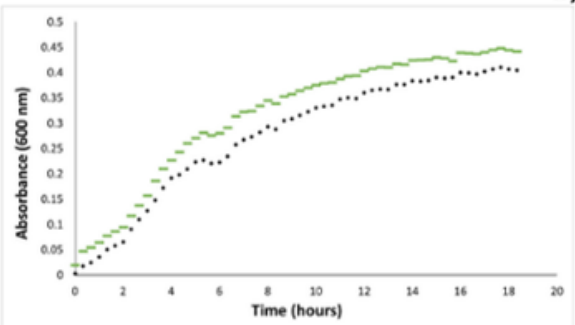

- Mixed wort $\quad$ - Zinc $5.25 \mathrm{ppm}$

h)

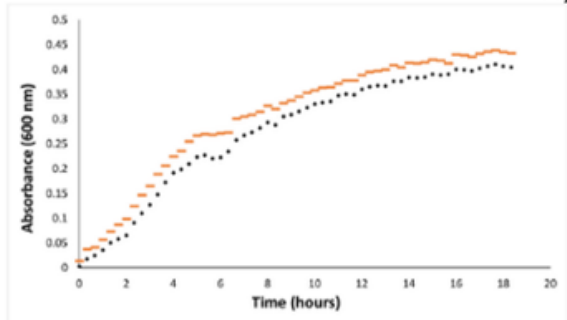

- Mixed wort $\quad-$ Potassium $311 \mathrm{ppm}$

k)

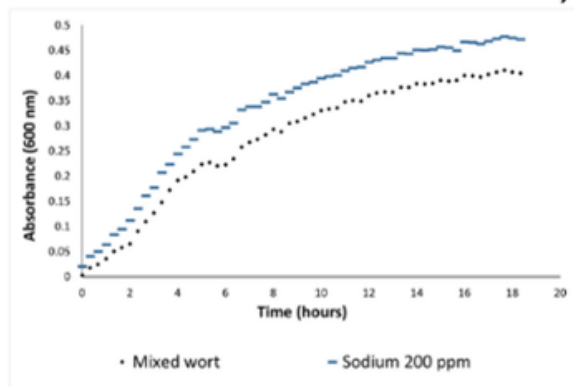

c)

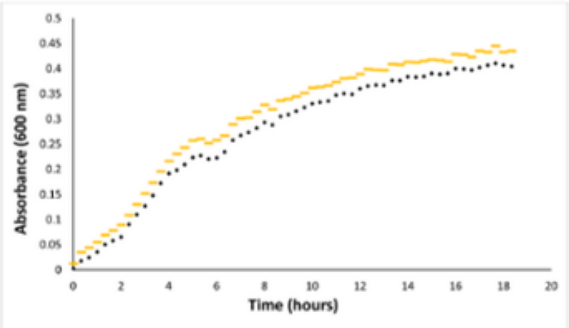

- Mixed wort - Magnesium $135 \mathrm{ppm}$

f)

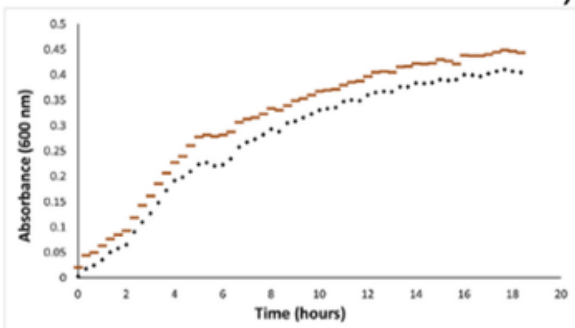

- Mixed wort $\quad$ - Iron $0.2 \mathrm{ppm}$

i)

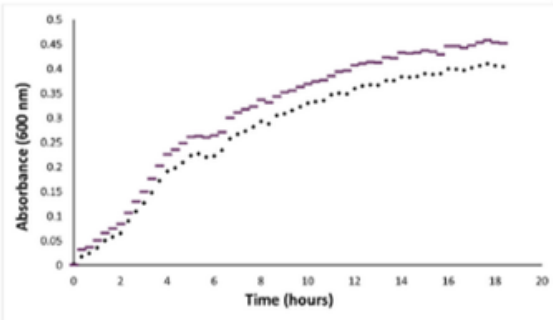

- Mixed wort $\quad-$ Cobalt $10 \mathrm{ppm}$

l)

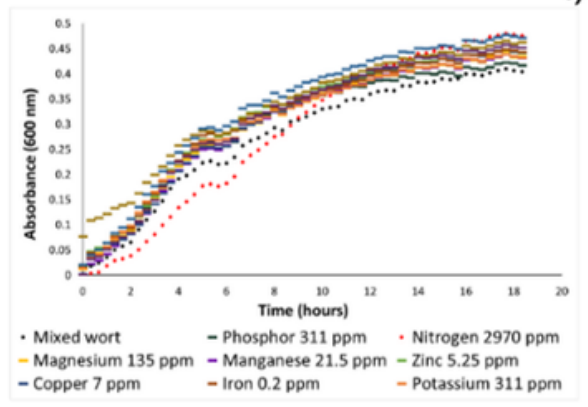

Figure 1

Nutrients' supplementation impacts on the Ethanol Red growth kinetics. I) Ethanol Red growth kinetic was assessed in twelve conditions. The yeast growth profile in the mixed wort with no supplementation was compared to the yeast growth profile in the mixed wort supplemented with a) phosphorus, b) nitrogen, c) magnesium, d) manganese, e) zinc, f) iron g) copper, h) potassium, i) cobalt, j) calcium and k) sodium. 


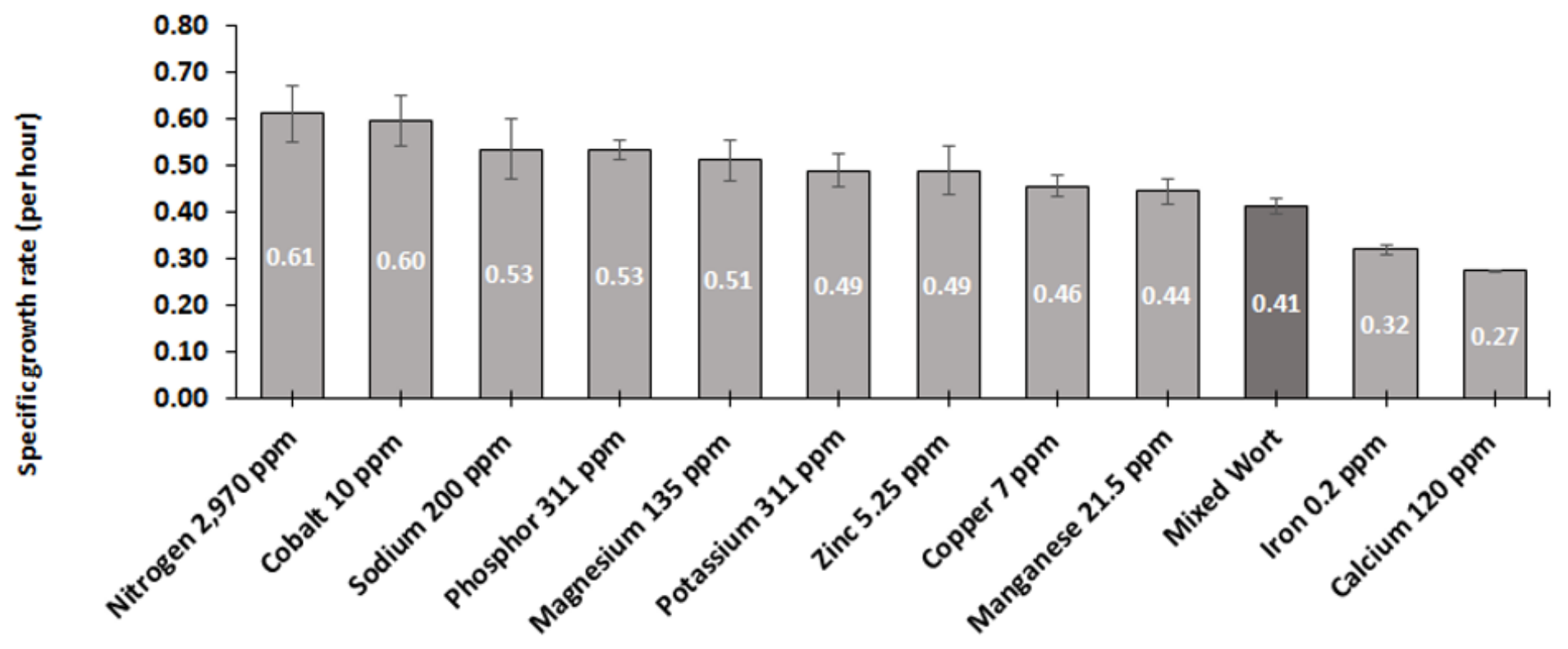

Supplemented nutrient concentration (ppm)

Figure 2

Nutrients' supplementation impacts on the Ethanol Red specific growth rate
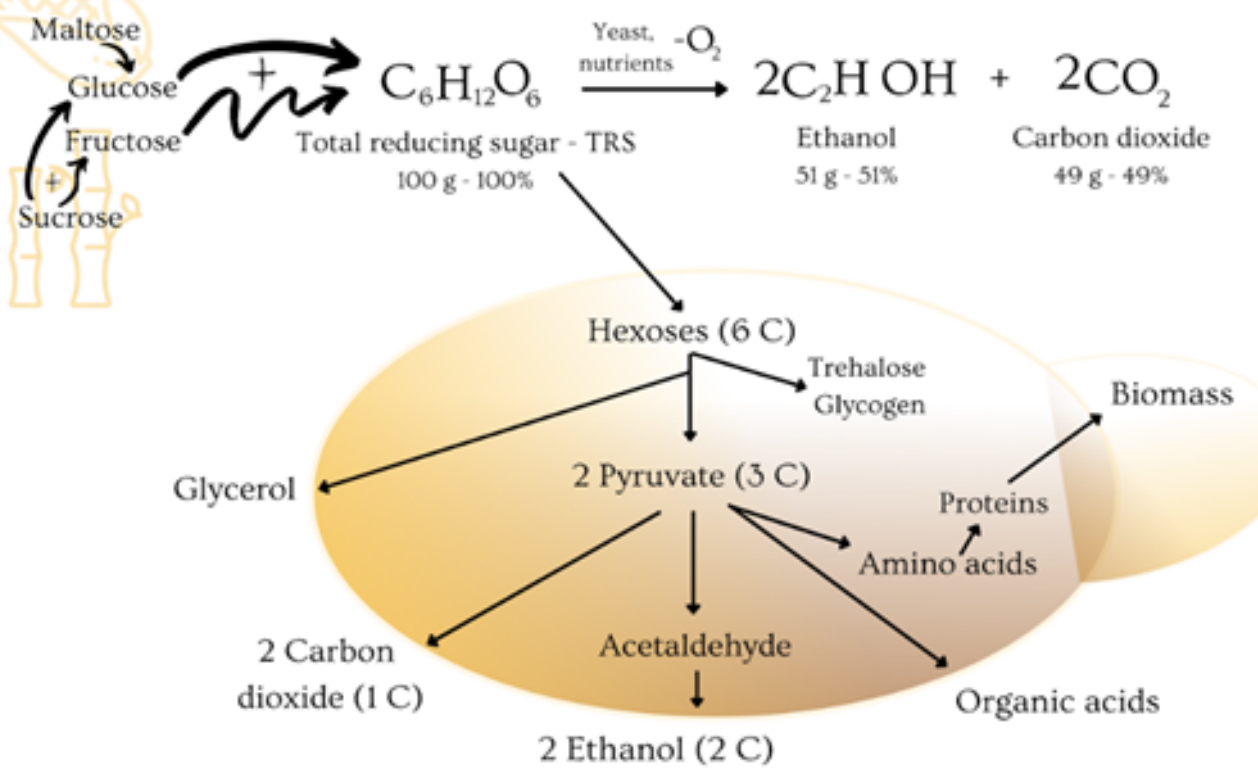

Figure 3

Schematic representation of chemical equation carried out by the yeast in alcoholic fermentation as well as a summarized description of its metabolism during the process. 


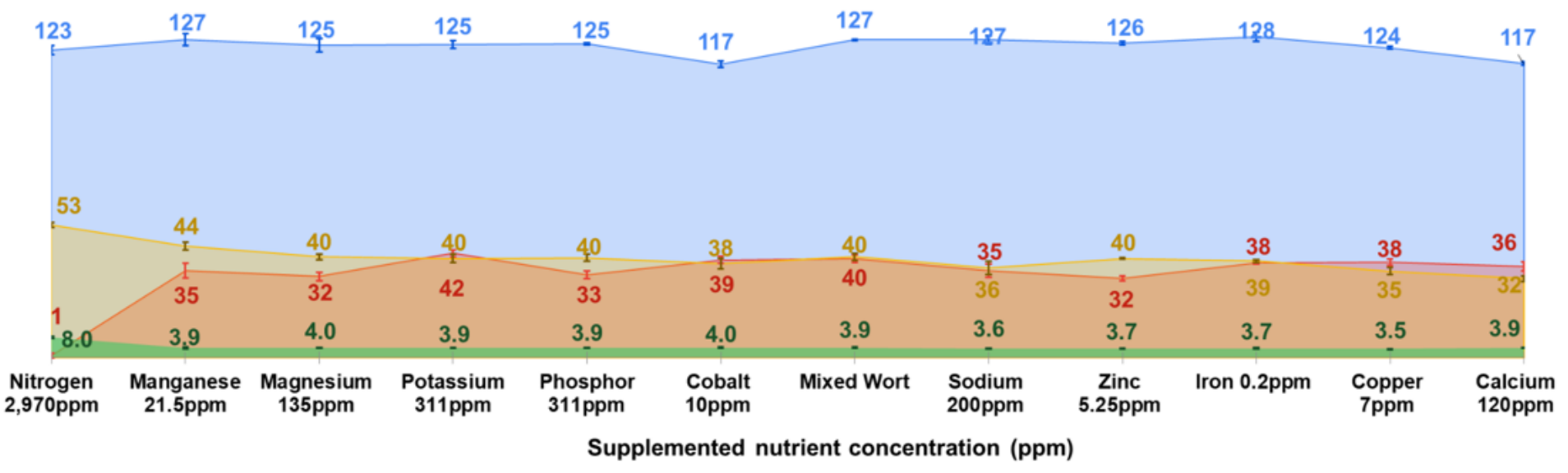

\section{Figure 4}

Ethanol, glycerol and the initial and residual TRS in the wort mixed wort before and after alcoholic fermentation

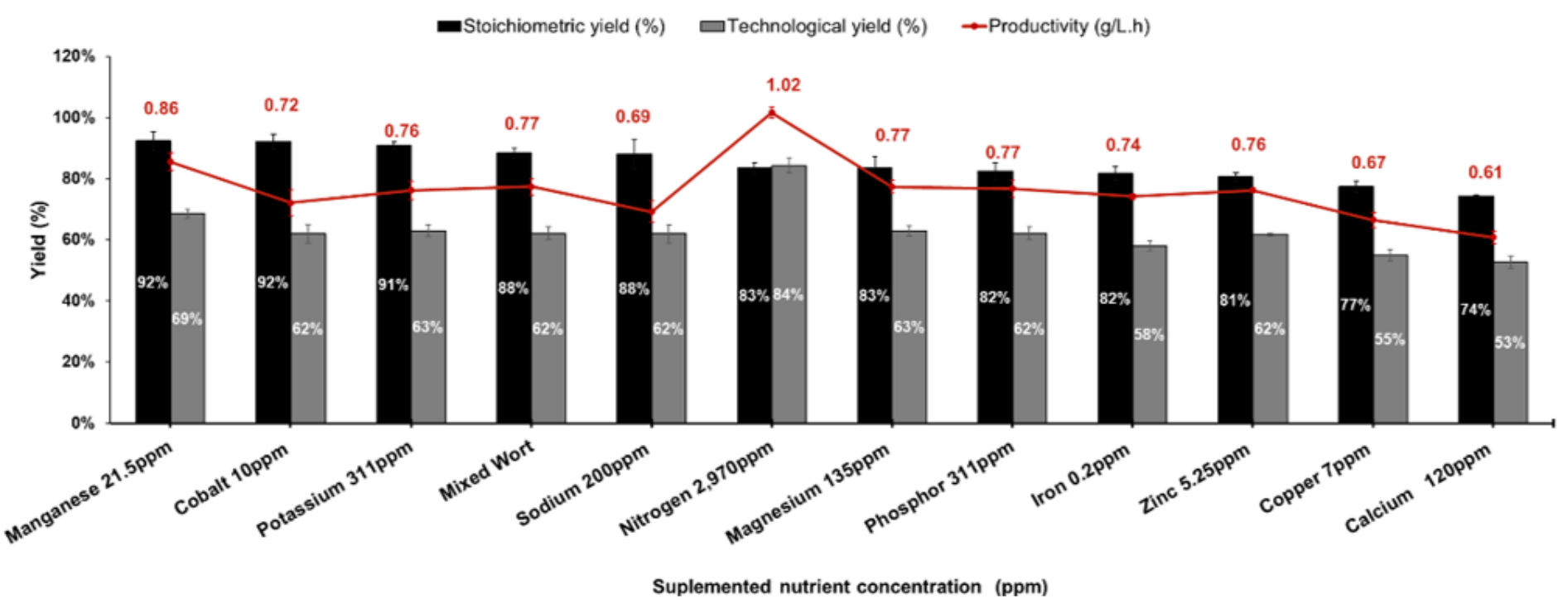

\section{Figure 5}

Nutrients supplementation's impacts on the alcoholic fermentation 


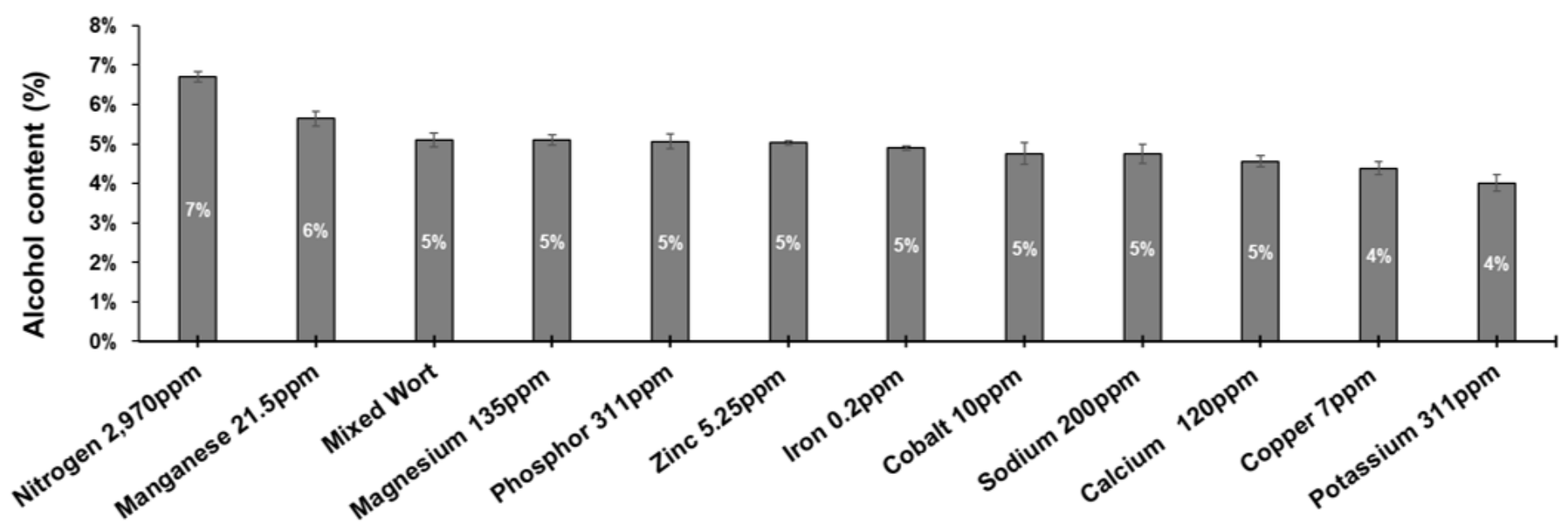

Supplemented nutrient concentration (ppm)

Figure 6

Ethanol content presented in the fermented mixed wort

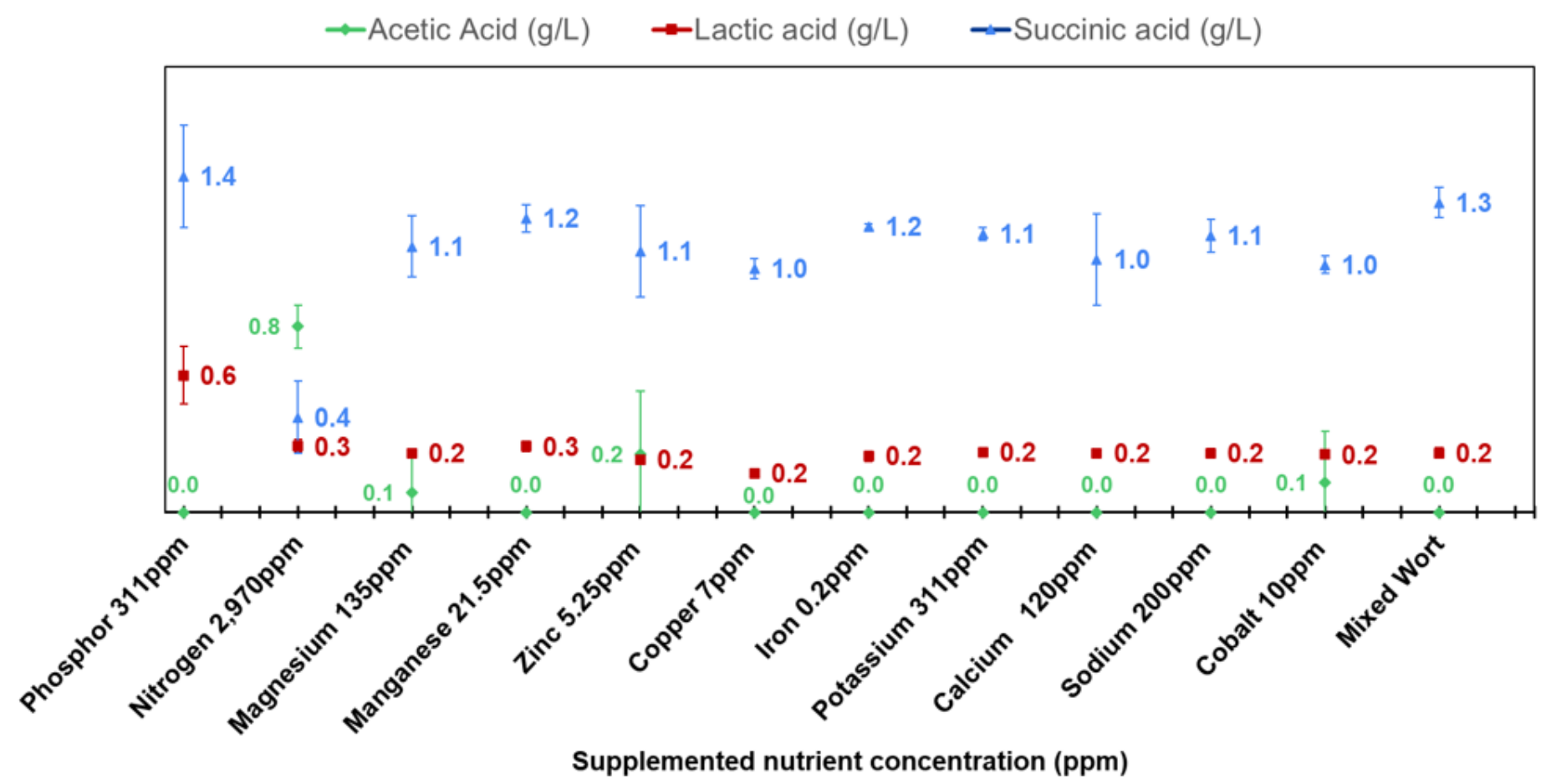

Figure 7

Organic acids concentrations in the fermented mixed wort

\section{Supplementary Files}

This is a list of supplementary files associated with this preprint. Click to download. 
- GraphicalAbstract.png

Page 24/24 